\title{
Lactose malabsorption is a risk factor for decreased bone mineral density in pancreatic insufficient cystic fibrosis patients
}

\author{
Edyta Madry ${ }^{1}$, Beata Krasińska ${ }^{2}$, Sławomira Drzymała-Czyż ${ }^{3}$, Dorota Sands ${ }^{4}$, Aleksandra Lisowska ${ }^{3}$, \\ Philip Grebowiec $^{3}$, Alina Minarowska ${ }^{5}$, Beata Oralewska ${ }^{6}$, Przemyslaw Mańkowski ${ }^{7}$, Jerzy Moczko ${ }^{8}$ \\ and Jarosław Walkowiak ${ }^{\star, 3,9}$
}

As decreased bone mineral density (BMD) is a common problem in cystic fibrosis (CF) and milk products may have pivotal dietary role affecting BMD, we aimed to assess the potential influence of adult-type hypolactasia (ATH) and lactose malabsorption (LM) on BMD in adolescent and young adult patients. In 95 CF pancreatic-insufficient patients aged 10-25 years (without liver cirrhosis, steatosis and cholestasis, diabetes mellitus, systemic glucocorticoid therapy), lumbar BMD, the nutritional status, pulmonary function, vitamin D3 concentration, calcium intake and single-nucleotide polymorphism upstream of the lactase gene were assessed. In subjects with the $-13910 \mathrm{C} / \mathrm{C}$ genotype predisposing to ATH, the presence of LM was determined with the use of a hydrogen-methane breath test (BT). BMD and calcium intake were significantly lower in patients with the $\mathrm{C} / \mathrm{C}$ genotype $(\boldsymbol{P}<0.028$ and $P<0.043$, respectively). The abnormal BMD was stated more frequently in patients with the $\mathrm{C} / \mathrm{C}$ genotype $(P<0.042)$ and with $\mathrm{LM}(\boldsymbol{P}<0.007)$. BMD, daily calcium intake and serum vitamin $\mathrm{D}$ concentration were significantly lower in LM subjects than in the other patients $(P<0.037, P<0.000004$ and $P<0.0038$, respectively). In logistic regression analysis, the relationship between examined parameters and BMD, was found to be statistically significant $(P<0.001)$. However, only standardized body weight and LM were documented to influence BMD $(P<0.025$ and $P<0.044$, respectively). In conclusion, LM seems to be an independent risk factor for decreased BMD in CF patients.

European Journal of Human Genetics (2012) 20, 1092-1095; doi:10.1038/ejhg.2012.52; published online 28 March 2012

Keywords: cystic fibrosis; bone mineral density; adult-type hypolactasia; lactose malabsorption

\section{INTRODUCTION}

Cystic fibrosis (CF) is the most common genetic disease within the Caucasian population. Approximately 60000 individuals with CF are currently living in North America and Europe, $40 \%$ of whom are adults. ${ }^{1}$ Although bone disease in CF was first described in $1979,{ }^{2,3}$ it has only recently received the proper attention as a result of the increase in life expectancy of CF patients. Their life span has increased from approximately 2 to 37 years of age over the past 3 decades, ${ }^{4}$ a time period which allows for the occurrence of bone disease. Decreased bone mineral density (BMD) is a common problem in this population, which affects quality of life and contributes to morbidity. A decrease in the quantity of bone minerals can cause pathological fractures and kyphosis, leading to intensified pain and decreased lung function. Severe bone disease may result in exclusion in qualification for lung transplantation, a life-saving treatment for individuals with CF. ${ }^{1,5}$

Patients with CF have many risk factors for reduced BMD. Important contributing conditions include: malabsorption of vitamin $\mathrm{D},{ }^{6}$ poor nutritional status, ${ }^{7,8}$ low physical activity, ${ }^{9}$ glucocorticoid therapy ${ }^{7}$ and delayed pubertal maturation or early hypogonadism. ${ }^{8}$ Additionally, chronic pulmonary inflammation due to an increase in serum cytokine levels may stimulate increased bone resorption and decreased bone formation. ${ }^{10}$

Optimal nutrition, vital for reaching and maintaining proper bone mass, remains a key-challenge in patients with CF. Most of them require a high-energy diet, and those with exocrine pancreatic insufficiency should also receive pancreatic enzyme replacement therapy. ${ }^{11,12}$ The deficiency of pancreatic elastase-1 (not included in pancreatic supplements), the enzyme necessary for digestion of elastin fibers (a component of meat), points to dairy products as being a potentially important source of protein. Moreover, calcium and vitamin D intake from dairy products, two nutrients that are crucial nutrients for bone accrual and mineralization, should be also considered.

Adult-type hypolactasia (ATH) is the most common genetically determined cause of milk intolerance in children, adolescents and

${ }^{1}$ Department of Physiology, Poznań University of Medical Sciences, Poznań, Poland; ${ }^{2}$ Department of Hypertension, Angiology and Internal Medicine, Poznań University of Medical Sciences, Poznań, Poland; ${ }^{3}$ Department of Pediatric Gastroenterology and Metabolism, Poznań University of Medical Sciences, Poznań, Poland; ${ }^{4}$ Department of Pediatrics, Mother and Child Health Institute, Warszawa, Poland; ${ }^{5}$ Department of Human Anatomy Medical, University of Białystok, Białystok, Poland; ${ }^{6}$ Department of Pediatric Gastroenterology, Hepatology and Immunology, Child Memorial Health Institute, Warszawa, Poland; 7 Department of Paediatric Surgery, Traumatology and Urology, Poznań University of Medical Sciences, Poznań, Poland; ${ }^{8}$ Department of Computer Science and Statistics, Poznań University of Medical Sciences, Poznań, Poland; ${ }^{9}$ Department of Dietetics, Chair of Human Nutrition and Hygiene, Poznań University of Life Sciences, Poznań, Poland

${ }^{*}$ Correspondence: Professor J Walkowiak, Department of Pediatric Gastroenterology and Metabolism, 1st Chair of Pediatrics, University of Medical Sciences, Szpitalna 27/33, Poznań 60-572, Poland. Tel: +48 61 8480310; Fax: +48 61 8472685; E-mail: jarwalk@ump.edu.pl

Received 18 November 2011; revised 2 February 2012; accepted 10 February 2012; published online 28 March 2012 
adults and the most common enzyme deficiency in humans. ${ }^{13}$ Lactase (LCT (MIM 603202)) is necessary for the digestion of lactose, the major carbohydrate found in milk. ${ }^{14}$ ATH inherited as an autosomal recessive trait leads to the downregulation of LCT activity in the intestinal mucosa (hypolactasia) and is the main reason of exclusion milk products from the diet worldwide. ${ }^{15,16}$ The homozygous form of allelic variant $\mathrm{C}$ at position $13910\left(\mathrm{C}_{\mathrm{C}} \mathrm{C}_{-13910}\right)$ upstream of the LCT gene (NM_005915.4:c.1917+326C > T; rs4988235) is strongly associated with ATH, whereas the homo- or heterozygous genotype of $\mathrm{T}$ allele (T/T -13910 or $\left.\mathrm{C} / \mathrm{T}_{-13910}\right)$ results in lactase persistence. ${ }^{17} \mathrm{LCT}$ activity reduction is a process that occurs progressively over time; hence, to determine the current clinical LCT state, it is necessary to use additional methods like an intestinal biopsy or a non-invasive one, such as hydrogen or hydrogen-methane breath test.

Only recently has it been demonstrated that the percentage of $\mathrm{CF}$ subjects with a genotype predisposing to ATH is similar to that observed in the healthy Caucasian population, which exceeds $30 \%$. However, lactose malabsorption (LM), as a clinical manifestation of ATH in young people, is significantly less frequent in healthy subjects and CF patients. ${ }^{18}$

Taking into account the expected pivotal dietary role of milk products in CF subjects, the aim of the study is to assess the potential influence of ATH and LM on BMD in adolescent and young adult patients.

\section{SUBJECTS AND METHODS}

A total of 95 CF patients of Polish origin aged 10-25 years ( 49 females and 46 males) with given consent were entered into the study.

The inclusion criteria comprised of the following:

- 10-25 years of age,

- a forced expiratory volume in $1 \mathrm{~s}$ (FEV 1) $>40 \%$,

- exocrine pancreatic insufficiency (fecal elastase- $1<100 \mu \mathrm{g} / \mathrm{g}$ ).

The exclusion criteria comprised of the following:

- liver cirrhosis, steatosis and cholestasis,

- diabetes mellitus,

- systemic glucocorticoid therapy.

Diagnosis of CF was based on history, clinical manifestation and increased sweat chloride concentrations, and confirmed by the CFTR gene analysis. The following mutations on alleles were found $(n)$ : F508del (132), CFTR dele2,3(21kB) (12), N1303K (6), 1717-1G-A (6), R533X (4), G542X (3), 2143delT (2), W1282X (2), 2184insA (2), G551D (1), 622GA (1), LT2143 (1), unknown mutations (18). A total of 56 patients were F508del homozygous and 20 were F508del heterozygous.

In all study participants, the nutritional status, lumbar BMD, pulmonary function, serum vitamin D3 concentration, calcium intake, and singlenucleotide polymorphism upstream of the lactase gene were assessed. In subjects with the $-13910 \mathrm{C} / \mathrm{C}$ genotype (which predisposes to ATH), the presence of LM was determined with the use of a hydrogen-methane BT. The details of the applied methodologies concerning genetic testing and hydrogen-methane breath testing are described elsewhere. ${ }^{18,19}$ BMD was assessed in the lumbar spine (L2-4) with the use of dual-emission X-ray absorptiometry, bone densitometer Lunar DPX-IQ; version 4.7e ( Madison, WI, USA). A BMD value of $<-1$ was assumed to be abnormal. In order to verify pulmonary function, the FEV1 expressed as a percentage of the vital capacity of lungs was determined. Serum vitamin D concentration was assessed in the fasting venous blood using DiaSorin RIA Double Antibody assay (DiaSorin, Stillwater, MN, USA). All subjects completed a 7-day food intake diary in order to assess daily calcium intake. ${ }^{20}$ Body weight and height were expressed as $Z$-scores (age- and sex-specific SD scores). ${ }^{21}$

The differences in clinical parameters between the subgroups with various $-13910 \mathrm{C} / \mathrm{T}$ lactase promoter genotypes, as well as between subjects with normal lactose absorption (NLA) and LM were analyzed using the WhitneyMann test. Moreover, the differences in the distribution of normal/abnormal $\mathrm{BMD}$ in the selected groups were compared using $\chi^{2}$ test. The influence of clinical parameters on the presence of abnormal BMD was determined with a use of logistic regression analysis. All statistical analysis were performed using Statistica 9.1. (StatSoft Inc., Tulsa, OK, USA, 2010).

The protocol of the investigation was approved by the Bioethical Committee of the Poznań University of Medical Sciences, Poland.

\section{RESULTS}

The detailed characteristic of the group has been summarized in Table 1. The distribution of normal and abnormal BMD in subgroups of CF patients has been presented in Table 2. The abnormal BMD was stated more frequently in patients with the $\mathrm{C} / \mathrm{C}$ genotype and with LM.

Clinical parameters of subgroups with different $-13910 \mathrm{C} / \mathrm{T}$ lactase promoter genotypes have been listed in Table 3. BMD and calcium intake were significantly lower in patients with the $\mathrm{C} / \mathrm{C}$ genotype than in the other subgroups. On the other hand, those patients were significantly older.

Clinical parameters of subgroups with LM and NLA have been presented in Table 4. BMD, daily calcium intake and serum vitamin D concentration were significantly lower in LM subjects than in NLA individuals.

Through the use of logistic regression analysis, the relationship between previously mentioned factors (age, body weight and height, the presence of the F508del and $-13910 \mathrm{C} / \mathrm{C}$ genotype, lung function, calcium intake and vitamin $\mathrm{D}$ concentration) and the studied variable, BMD, was found to be statistically significant $(P<0.001)$. Standardized body weight and LM were documented as an independent risk factors of decreased BMD $(P<0.025$ and $P<0.044$, respectively; OR (95\% CI): 3.33 (1.17-9.52) and 13.11 (1.07-160.63), respectively).

\section{DISCUSSION}

We proved in the present study that an abnormal BMD is significantly more frequent in CF patients with the C/C genotype and with LM. However, logistic regression showed that LM exclusively is a statistically significant risk factor for low BMD. According to a review of

Table 1 Characteristic of the studied group

\begin{tabular}{|c|c|c|c|c|c|c|c|c|}
\hline $\begin{array}{l}C F \\
n=95\end{array}$ & $\begin{array}{l}\text { Age } \\
\text { (year) }\end{array}$ & $\begin{array}{c}\text { Body mass } \\
\text { (Z-score) }\end{array}$ & $\begin{array}{c}\text { Body height } \\
\text { (Z-score) }\end{array}$ & $\begin{array}{c}\text { FEV1 } \\
(\%)\end{array}$ & $\begin{array}{c}C a \\
(\% R D A)\end{array}$ & $\begin{array}{c}D 3 \\
(n g / m l)\end{array}$ & $\begin{array}{c}E 1 \\
(\mu g / g)\end{array}$ & $B M D$ \\
\hline Median & 13.6 & -1.01 & -0.61 & 77.1 & 99.0 & 22.5 & 8 & -1.30 \\
\hline First quartile & 11.9 & -1.44 & -2.04 & 66.6 & 76.3 & 13.3 & 3 & -1.90 \\
\hline Third quartile & 16.2 & -0.38 & 0.01 & 94.1 & 124.9 & 29.9 & 18 & -0.54 \\
\hline Mean & 14.2 & -0.88 & -0.91 & 79.2 & 100.3 & 21.9 & 12.8 & 1.28 \\
\hline \pm SEM & \pm 0.3 & \pm 0.09 & \pm 0.14 & \pm 2.0 & \pm 3.7 & \pm 1.0 & \pm 1.7 & \pm 0.09 \\
\hline
\end{tabular}

Abbreviation: BMD, bone mineral density. 
the literature related to the topic, this is the first study evaluating the impact of LM on BMD in the CF population, in which-beyond lung disease-nutritional status and bone disease are nowadays the key life-limiting factors. ${ }^{5}$ In the present study, several risk factors associated with comorbid conditions and CF treatment, which could have had a possible influence on BMD, were eliminated from the analysis through the use of restrictive inclusion and exclusion criteria. The results of our study confirmed the importance of nutritional status for BMD, which remains in line with the findings by Gray et $a^{22}$ and Tschopp et $a^{23}$ in which low body mass index/ body weight has been linked to low BMD, especially in adolescents and young adults.

It is expected that in the general adult population, ${ }^{24}$ aging is associated with a lowering of BMD. In the present study, a tendency towards such a relationship was stated ( $P=0.099$ for both equations). It seems that limited range of age in the subjects studied might be responsible for the lack of statistical significance. The age of the patients studied ranged from 10 to 25 years. However, they were predominantly young adolescents (median age of 13.6 years). King

Table 2 The distribution of normal and abnormal bone mineral density (BMD) in subgroups of CF patients with different genotypes of lactase promoter gene and with different clinical lactose status

\begin{tabular}{|c|c|c|c|}
\hline \multirow[b]{2}{*}{ Group } & \multicolumn{2}{|c|}{$B M D$} & \multirow[b]{2}{*}{$\begin{array}{c}\text { Statistical } \\
\text { significance }\end{array}$} \\
\hline & $\begin{array}{c}\text { Normal } \\
n(\%)\end{array}$ & $\begin{array}{c}\text { Abnormal } \\
n(\%)\end{array}$ & \\
\hline C/C genotype & $12(23.5)$ & $39(76.5)$ & $P=0.042$ \\
\hline Other genotypes ${ }^{a}$ & $19(43.2)$ & $25(56.8)$ & \\
\hline NLA & $30(40.0)$ & $45(60.0)$ & $P=0.007$ \\
\hline LM & $1(5.0)$ & $19(95.0)$ & \\
\hline
\end{tabular}

Abbreviations: LM, lactose malabsorption; NLA, normal lactose absorption.

${ }^{\mathrm{a}} \mathrm{C} / \mathrm{T}$ or $\mathrm{T} / \mathrm{T}$ genotype. et al. ${ }^{25}$ did not observe a relationship between age and BMD, which should awaken a state of reflection, given that their studied group consisted of adults aged 19-59. In light of other clinical studies, the annualized rate of BMD loss in CF patients approaches to those seen in postmenopausal women. ${ }^{26,27}$ Certainly, the monitoring of bone health and the starting of early intervention in CF patients is crucial owing to the poor bone status at a young age, which deteriorates as the patient ages. ${ }^{5}$

Interestingly, King et $a^{25}$ have shown that the presence of the delF508 mutation is an independent risk factor of reduced BMD. We did not confirm this observation (logistic regression; $P=0.732$ and 0.815 , respectively). A possible explanation of this discrepancy may be the criteria for the study group selection. In contrary to the abovementioned study, we factored into the analysis only pancreatic insufficient patients. Comparing the results, we could speculate that rather mild CFTR mutations might exert a protective effect, promoting milder disease and a better clinical status in regards to BMD.

There have been several studies indicating that CF patients in childhood and puberty achieve approximately half of the bone density of that in their healthy counterparts. ${ }^{8,28,29}$ Physiologically, bone mineralization requires optimal diet, with adequate protein and calorie intake, adequate calcium, vitamin $\mathrm{D}$ and $\mathrm{K}$ supply, and sufficient physical activity. CF can virtually disrupt each of these elements. ${ }^{30}$ Calcium is an important component for bone metabolism and is essential for the maintenance of skeletal health. Schulze et al ${ }^{31}$ showed that increased calcium absorption in young women with CF was associated with increased rates of bone calcium deposition. One of the most important sources of calcium and vitamin D in the diet is milk and dairy products. Potentially, LM could be an important factor influencing the biological effect of these products consumption. In the present study, we verified LM with the use of BT. In the subgroup of patients with LM, calcium intake (52.5 vs 106.0\% RDA; $P=0.000004)$ and vitamin $\mathrm{D}$ serum concentration (13.8 vs 24.3; $P=0.0038)$ were

Table 3 Clinical parameters of subgroups with different $-13910 \mathrm{C} / \mathrm{T}$ lactase promoter genotype

\begin{tabular}{|c|c|c|c|c|}
\hline \multirow{2}{*}{$\begin{array}{l}\text { Studied parameter median } \\
\text { (first-third quartile) }\end{array}$} & \multicolumn{3}{|c|}{ Genotype (n) } & \multirow{2}{*}{$\begin{array}{c}\text { Statistical significance } \\
\text { CC vs others }\end{array}$} \\
\hline & $C / C(41)$ & $C / T(24)$ & $T / T(20)$ & \\
\hline BMD (Z-score) & $-1.42(-2.07:-1.08)$ & $-1.05(-1.67:-0.45)$ & $-1.15(-1.64:-0.38)$ & $P=0.028$ \\
\hline Age (year) & $14.9(12.6-16.6)$ & $14.1(11.6-15.7)$ & $12.0(10.9-14.2)$ & $P=0.043$ \\
\hline Body weight (Z-score) & $-1.10(-1.57:-0.35)$ & $-0.96(-1.15:-0.45)$ & $-0.88(-1.29:-0.17)$ & $P=0.247$ \\
\hline Body height (Z-score) & $-0.62(-2.15:-0.04)$ & $-0.60(-1.09:-0.29)$ & $-0.54(-1.11:-0.25)$ & $P=0.366$ \\
\hline $\mathrm{Ca}(\% \mathrm{RDA})$ & $96.2(60.3-121.6)$ & $109.2(93.3-129.2)$ & $102.7(84.2-128.7)$ & $P=0.043$ \\
\hline Vitamin D3 (ng/ml) & $21.2(13.4-29.6)$ & $21.7(13.4-30.2)$ & $23.8(15.3-29.1)$ & $P=0.973$ \\
\hline FEV1 (\%) & $75.5(65.4-94.8)$ & $83.0(67.5-94.0)$ & $76.0(70.0-88.1)$ & $P=0.908$ \\
\hline
\end{tabular}

Table 4 Clinical parameters of CF patients with lactose malabsorption (LM) and normal lactose absorption (NLA)

\begin{tabular}{|c|c|c|c|}
\hline Studied parameter median (first-third quartile) & $L M, \mathrm{n}=20$ & $N L A, \mathrm{n}=75$ & Statistical significance \\
\hline BMD (Z-score) & $-1.53(-1.91:-1.17)$ & $-1.24(-1.90:-0.44)$ & $P=0.037$ \\
\hline Age (year) & $15.2(12.2-17.6)$ & $16.6(11.2-15.6)$ & $P=0.236$ \\
\hline Body weight (Z-score) & $-0.71(-1.62:-0.39)$ & $-1.03(-1.41:-0.36)$ & $P=0.867$ \\
\hline Body height (Z-score) & $-0.16(-2.79:-0.24)$ & $-0.63(-1.67:-0.14)$ & $P=0.700$ \\
\hline $\mathrm{Ca}(\% \mathrm{RDA})$ & $52.5(46.3-78.5)$ & $106.0(85.8-128.7)$ & $P=0.000004$ \\
\hline Vitamin D3 (ng/ml) & $13.8(12.1-15.8)$ & $24.3(15.0-31.5)$ & $P=0.0038$ \\
\hline FEV1 (\%) & $77.8(74.4-92.1)$ & $75.0(64.0-94.1)$ & $P=0.066$ \\
\hline
\end{tabular}


significantly lower than those in the NLA subjects (Table 4). Body weight and height did not differ between groups. However, BMD was significantly lower in patients with LM ( $Z$-score -1.53 vs -1.24 ; $P=0.037$ ). Although vitamin $\mathrm{D}$ levels and calcium intake were very low, we did not find a direct relationship with BMD. To some extent, this does seem to be justified, because BMD reflects bone health over the lifetime of the patient, and current vitamin D concentrations may fluctuate from season to season. ${ }^{1,25}$ On the other hand, both parameters are simply related to LM. Nonetheless, the use of logistic regression for analysis of the study results has shown the strong relationship of BMD with both body weight $(P<0.025)$ and LM $(P<0.044)$. When considering the influence of the -13910 $\mathrm{C} / \mathrm{C}$ genotype using logistic regression analysis, a tendency towards the influence of calcium intake was found $(P<0.087)$. This would point to a potential effect of dairy products ingestion. Moreover, calcium intake was significantly lower $(P<0.043)$ in patients with a $-13910 \mathrm{C} / \mathrm{C}$ genotype than in the other CF subjects. However, as was mentioned earlier, this seems to be simply related to LM.

As documented in the present study, LM is an independent risk factor of low BMD in pancreatic insufficient CF subjects. This points to a need for specific dietary modification in this group of patients. Furthermore, the possible asymptomatic course of LM, as well as a frequent incidence of abdominal discomfort in CF patients, which may be identical to LM symptoms, indicates the need of performing tests for early LM detection. We strongly recommend that it should be carried out with the use of BT, as it is a reliable, non-invasive and inexpensive procedure.

A large amount of resources spent on dietary education and nutritional support brings about desired results and contributes in improving the body mass index and nutritional status of the $\mathrm{CF}$ population, which in turn extends the life expectancy of CF patients. ${ }^{20}$ In the present study, we have proved that LM, not the presence of the F508del mutation or the $-13910 \mathrm{C} / \mathrm{C}$ genotype, is an independent risk factor for decreased $\mathrm{BMD}$ in $\mathrm{CF}$ patients. Therefore, we recommend the consumption of small doses of dairy products divided between meals during the day for CF lactose malabsorbers. It is also worth putting an emphasis on the intake of fermented products, which are better tolerated than milk owing to their 'autodigestive' capacity. This stems from their content of $\beta$-galactosidase, the enzyme that may act in lactose digestion and may change gastric emptying and small intestine transit. ${ }^{32-34}$ Additional work is needed to optimize the nutritional standards for the dairy products in CF lactose malabsorbers, so as to contribute to the prevention or reversal of poor bone health in this group of patients.

\section{CONCLUSION}

$\mathrm{LM}$ seems to be an independent risk factor for decreased BMD in $\mathrm{CF}$ patients.

\section{CONFLICT OF INTEREST}

The authors declare no conflict of interest.

\section{ACKNOWLEDGEMENTS}

Supported by the Ministry of Science and Higher Education (Grant No. N407 2110 33) and Poznań University of Medical Sciences (University grant).

1 Aris RM, Merkel PA, Bachrach LK et al: Guide to bone health and disease in cystic fibrosis. J Clin Endocrinol Meta 2005; 90: 1888-1896.
2 Mischler EH, Chesney PJ, Chesney RW, Mazess RB: Demineralization in cystic fibrosis detected by direct photon absorptiometry. Am J Dis Child 1979; 133: 632-635.

3 Hahn TJ, Squires AE, Halstead LR, Strominger DB: Reduced serum 25-hydroxyvitamin $D$ concentration and disordered mineral metabolism in patients with cystic fibrosis J Pediatr 1979; 94: 38-42.

4 Cystic Fibrosis Foundation. http://www.cff.org/aboutcf/faqs/\#What is the life expectancy for people who have CF \%28in the United States\%29?/(accessed 9 Nov 2011).

5 Gore AP, Kwon SH, Stenbit AE: A roadmap to the brittle bones of cystic fibrosis J Osteoporos, Article ID926045: 1-10. Published online 2011.

6 Ott SM, Aitken ML: Osteoporosis in patients with cystic fibrosis. Clin Chest Med 1998; 19: 555-567.

7 Conway SP, Morton AM, Oldroyd B et al: Osteoporosis and osteopenia in adults and adolescents with cystic fibrosis: prevalence and associated factors. Thorax 2000; 55 : 798-804.

8 Bhudhikanok GS, Wang MC, Marcus R, Harkins A, Moss R, Bachrach LK: Bone acquisition and loss in children and adults with cystic fibrosis: a longitudinal study J Pediatr 1998; 133: 18-27.

9 Aris RM, Lester GE, Camaniti M et al: Efficacy of alendronate in adults with cystic fibrosis with low bone density. Am J Respir Crit Care Med 2004; 169: 77-82.

10 Aris RM, Stevens A, Ontjes DA et al: Adverse alterations in bone metabolism are associated with lung infection in adults with cystic fibrosis. Am J Respir Crit Care Med 2000; 162: 1674-1678

11 Walkowiak J: Assessment of maldigestion in cystic fibrosis. J Pediatr 2004; 145 : 285-287.

12 Walkowiak J, Nousia-Arvanitakis S, Henker J, Stern M, Sinaasappel M, Dodge JA: Indirect pancreatic function tests in children. J Pediatr Gastroenterol Nutr 2005; 40: 107-114.

13 Semenza G, Auricchio S, Mantei N: Small-intestinal disaccharidases; in Scriver CR (eds) The metabolic and molecular basis of inherited disease. New York: McGraw-Hill, 2001; 1623-1650.

14 Ingram CJ, Mulcare CA, Itan Y, Thomas MG, Swallow DM: Lactose digestion and the evolutionary genetics of lactase persistence. Hum Genet 2009; 124: 57991.

15 Heyman MB: Lactose intolerance in infants, children, and adolescents. Pediatrics 2006; 118: 127986.

16 Di Stefano M, Veneto G, Malservisi S et al: Lactose malabsorption and intolerance and peak bone mass. Gastroenterology 2002; 122: 1793-1799.

17 Enattah NS, Sahi T, Savilahti E et al: Identification of a variant associated with adult-type hypolactasia. Nat Genet 2002; 30: 233-237.

18 Madry E, Fidler E, Sobczyńska-Tomaszewska A et al: Mild CFTR mutations and genetic predisposition to lactase persistence in cystic fibrosis. Eur J Hum Genet 2011; 19: 748-752.

19 Madry E, Lisowska A, Kwiecień J et al: Adult-type hypolactasia and lactose malabsorption in Poland. Acta Biochim Pol 2010; 57: 585-588.

20 Walkowiak J, Przyslawski J: Five-year prospective analysis of dietary intake and clinical status in malnourished cystic fibrosis patients. J Hum Nutr Diet 2003; 16: 225-231.

21 Krawczynski M, Walkowiak J, Krzyzaniak A: Secular changes in body height and weight in children and adolescents in Poznan, Poland, between 1880 and 2000. Acta Paediatr 2003; 92: 277-282.

22 Grey $A B$, Ames RW, Matthews RD, Reid IR: Bone mineral density and body composition in adult patients with cystic fibrosis. Thorax 1993; 48: 589-593.

23 Tschopp 0, Boehler A, Speich R et al: Osteoporosis before lung transplantation: association with low body mass index, but not with underlying disease Am J Transplant 2002; 2: 167-172.

24 Schulman RC, Weiss AJ, Mechanick JI: Nutrition, bone, and aging: an integrative physiology approach. Curr Osteoporos Rep 2011; 9: 184-195.

25 King SJ, Topliss DJ, Kotsimbos $\mathrm{T}$ et al: Reduced bone density in cystic fibrosis: deltaf508 mutation is an independent risk factor. Eur Respir J 2005; 25: 54-61.

26 Aris RM, Lester GE, Caminiti M et al: Efficacy of alendronate in adults with cystic fibrosis with low bone density. Am J Respir Crit Care Med 2004; 169: 77-82.

27 Chapman I, Greville H, Ebeling PR et al: Intravenous zoledronate improves bone density in adults with cystic fibrosis (CF). Clin Endocrinol 2009; 70: 838-846.

28 Bianchi ML, Romano G, Saraifoger S, Costantini D, Limonta C, Colombo C: BMD and body composition in children and young patients affected by cystic fibrosis J Bone Miner Res 2006; 21: 388-396.

29 Buntain HM, Greer RM, Schluter PJ et al: Bone mineral density in Australian children, adolescents and adults with cystic fibrosis: a controlled cross sectional study Thorax 2004; 59: 149-155.

30 Sermet-Gaudelus I, Castanet M, Retsch-Bogart G, Aris R: Update on cystic fibrosis-related bone disease: a special focus on children. Paediatr Respir Rev 2009; 10: 134-142.

31 Schulze KJ, O'Brien KO, Germain-Lee EL, Booth SL, Leonard A, Rosenstein BJ: Calcium kinetics are altered in clinically stable girls with cystic fibrosis. J Clin Endocrinol Metab 2004; 89: 3385-3391.

32 Kolars JC, Levitt MD, Aouji M, Savaiano DA: Yogurt-an autodigesting source of lactose. N Engl J Med 1984; 310: 1-3.

33 Martini MC, Kukielka D, Savaiano DA: Lactose digestion from yogurt: influence of a meal and additional lactose. Am J Clin Nutr 1991; 53: 1253-1258.

34 Mạdry E, Krasińska B, Woźniewicz M et al: Tolerance of different dairy products in subjects with symptomatic lactose malabsorption due to adult type hypolactasia. Prz. Gastroenterol 2011: 5: 310-315. 